Europe's Journal of Psychology, 6(4), pp. 32-55

www.ejop.org

\title{
Posttraumatic stress among Palestinian adolescents in the Gaza Strip: An analysis of ev ent-related and demographic factors
}

\author{
Ibrahim Abu Nada (1) \\ Smadar Celestin-Westreich (1) \\ Wim Van den Broeck (1) \\ Leon-Patrice Celestin (2)
}

(1) Department of Clinical and Lifespan Psychology, Faculty of Psychology and Educational Sciences Vrije Universiteit Brussels (VUB), Belgium

(2) Department of Psychiatry, Hospital Simone Veil

\begin{abstract}
Objective: This study investigates the impact of ongoing traumatic events on Palestinian adolescents' posttraumatic stress according to event-related and demographic factors. Method: A sample of 368 Palestinian adolescents (49.2\% males, mean age 17.03) was drawn from different areas of the Gaza Strip. Students were investigated on exposure to traumatic events and posttraumatic stress symptoms (PTSS) and disorder (PTSD). Results: The mean number of traumatic events experienced by the adolescents was 9.9 (SD = 3.20). Boys were significantly more exposed than girls, as were adolescents living in villages compared to those living in Gaza city or refugee camps. Adolescents mainly and pervasively experienced objective, non-personal material exposure (such as witnessing bombardments) (85\% to $96 \%$ ) and media exposure (95\%). Up to $17 \%$ of the adolescents experienced direct, physical exposure (7\% personal injury), exposure through injury and death of relatives. In this context, two fifths of the adolescents experienced mild, two fifths moderate and one fifth severe PTSS. Remarkably, adolescents did not differ significantly in PTSS despite exposure differences across gender, place of residency and family income. Conclusion: Near half of the investigated adolescents living in the Gaza Strip experience moderate to severe levels of posttraumatic stress, for around one fifth this amounts to a probable posttraumatic stress disorder. These findings urge toward providing psychological support programs to Palestinian adolescents to enhance current wellbeing and limit further developmental risks. Furthermore, the findings suggest the need to investigate the role of appraisal and
\end{abstract}


coping to understand the pathways through which differences in trauma exposure lead to similar posttraumatic stress outcomes.

Keywords: Posttraumatic stress, traumatic events, adolescents, demographic, Gaza Strip, Palestinian

\section{Introduction}

Since the outbreak of the al-A qsa Intifada in late September 2000, Palestinian youth have been extensively exposed to traumatic events. These have ranged from witnessing bombardment of homes, schools and streets, through hearing about the killing of friends and relatives, to being personally injured. Such ongoing exposure raises questions about the psychologic al effects it exerts on adolescents. Exposure to traumatic events is known to increase the risks of both short-term and long-term mental health problems (Saigh, 1991; Thabet, Abed, and Vostanis, 1999). Youngsters living in conditions of war and military violence have been described as growing up too soon and taking premature political responsibilities (Boothby, Upton, Sultan, 1992). They are also known to be at high risk of developing posttraumatic stress symptoms or disorder (PTSS/PTSD) (Dyregrov, Gjestad, and Raundalen, 2002). In the past years, research about psychological outcomes after traumatic events has increased. However, relatively few studies specifically examine how adolescents' continuing exposure to trauma impacts on their wellbeing. Also, research conducted so far has remained inconclusive as regards the range and the intensity of these outcomes according to event-related and demographic determinants.

This study examines the prevalence of postraumatic stress in Palestinian adolescents living in the Gaza Strip. It also investigates to what extent these youth's stress reactions vary according to event-related and demographic factors. To this effect, we shall first briefly discuss the state of the literature regarding adolescents' PTSS after exposure to traumatic events and potential determinants in this context.

Posttraumatic stress in the face of chronic exposure to trauma:

From theory to empirical evidence

Briefly circumscribed, posttraumatic stress consists of typical reactions that arise after experiencing 'severe' traumatic event(s) or situation(s). They mainly include intrusive re-experiencing of the event(s), hyper arousal, and avoidance and numbness symptoms. The persistence hereof for more than a month will amount to a posttraumatic stress disorder (PTSD) as described by the DSM-IV diagnostic criteria 
(American Psychiatric Association, 2004; also see Instruments). From a more dynamic bio-psycho-social approach as conceptualized in the FACE ${ }^{\odot-m o d e l ~(F a c i l i t a t i n g ~}$ Adjustment of Cognition and Emotion), posttraumatic stress amounts to a series of cognitive and emotional adaptations reflecting the exposed individual's attempts to deal with overwhelming stressor(s). Posttraumatic stress is thus conceived as the more or less durable disruption, following traumatic experiences, of the adjustment between cognitive control and emotion regulation processes, with the first being bypassed (e.g. as regards executive functioning, memory and attention processes) by an intensified reactivity and modified biochemistry of the latter (e.g. as regards autonomous reactions, neurotransmitter functioning and neuronal connections) (Celestin-Westreich and Celestin, 2010). Overall, the evidence-base has demonstrated dose-response effects to this regard, namely, higher exposure levels trigger higher posttraumatic stress levels. However, while some events or situations will be ov erwhelmingly traumatic to most individuals, important variability also exists as to which experiences are traumatic to whom, to what extent and under which circumstances (Braun-Lewensohn, Celestin-Westreich, Celestin, Verleye, Verté, and Ponjaert-Kristoffersen, 2009a; Celestin-Westreich and Celestin, 2010; Kalantari and Vostanis, 2010; Powers, Halpern, Ferenschak, Gillihan, and Foa, 2010). From the above-cited $\mathrm{FACE}^{\odot}$ perspective, this happens as a function of the balance of personal, relational and environmental risk factors and resources for a given individual at a given time as well as throughout the life span.

For adolescents, posttraumatic stress proves crucial to their developmental pathways. Adolescence indeed tends to imply both sources of resilience and vulnerability toward PTSS/D. On the one hand, youngsters' brains are still developing which may facilitate resiliency through neuroplasticity, especially when supported by proper prevention and intervention strategies. On the other hand, particularly from middle adolescence on, strong stressors may precipitate preexisting difficulties and/or (genetical) predispositions toward diverse forms of psychopathology. Posttraumatic stress may therefore interfere in multifinal ways with middle to late adolescents' developmental tasks of distancing from parents and family, experimenting with diverse roles and identities in society and engaging tow ard adult functioning, the more so in societies where such roles are taken up relatively early in life. For example, trauma exposure may provoke procrastination in some adolescents while aggravating acting out in others. Hence, posttraumatic stress reactions during adolescence are never negligible (e.g. Cummings, Davies and Campbell, 2000; Finkelhor, 1995; Powers et al., 2010; Qouta, Punamaki, Montgomery, and El Sarraj, 2007). 
Despite these insights, the evidence-base concerning adolescents' pathways when confronted with continual exposure to sociopolitical disputes remains limited to date. In the first place, there is a clear need for empirical data as to which aspects of this exposure are determinant and under which circumstances.

Overall prevalence of posttraumatic stress in Palestinian youth

In recent years, a number of studies have started to assess the lev els of PTSS or PTSD among Palestinian youth given their widespread exposure to trauma. Indeed, between September 2000 and November 2005, over 26000 Palestinians under the age of 18 years, representing about $7.5 \%$ of the child and adolescent population, were injured in the context of the Al-Aqsa Intifada. Approximately $12 \%$ of the injured youngsters are now suffering from a permanent dis ability (PCBS, 2006). Overall, PTSS levels seem to range from $10 \%$ to $70 \%$ among the youth from the Gaza strip (Thabet et al., 1999; Qouta, Punamaki, and El Sarraj, 2003). In a study on 1000 school-aged Palestinian children, $54.7 \%$ reported experiencing at least one intense traumatic event in their lifetime and 34\% were diagnosed as having full PTSD (Khamis, 2000). In child populations from relativ ely comparable contexts, levels of PTSS ranged from 22 to $25 \%$ among Israeli and $27 \%$ among Lebanese children, through $48 \%$ among Cambodian refugee children and $52 \%$ among Bosnian youth (Kinzie, Sack, Angell, Manson, and Rath, 1986; Smith, Perrin, Yule, and Rabe 2001). Iraqi children whose shelter was destroyed by shelling showed the highest posttraumatic stress levels (7888\%) (Dyregrov et al., 2002).

The few studies specifically pertaining to Palestinian adolescents (aged 11 to 19 years) suggest that 11 to $16 \%$ suffer from low to mild, $33 \%$ to $49 \%$ from moderate and 33 to $54 \%$ severe levels of PTSS/D (e.g. Qouta et al., 2003).

Given these data, closer investigation is required to understand the wide range of posttraumatic stress reactions among Palestinian youth. For one, 'posttraumatic stress' levels tend to be diversely circumscribed across and even within studies, including either postraumatic stress symptoms (PTSS), disorder (PTSD, as defined by DSM criteria) or both. In short, there is a need to distinguish between PTSS and PTSD when reporting Palestinian adolescents' posttraumatic stress levels. Furthermore, to date these levels have mainly been investigated as a function of the degree of exposure. The broader trauma literature suggests that PTSS outcomes may also vary according to types of exposure, personal and other demographic factors (such as gender, age, and place of residency and family characteristics), as discussed hereafter. 
The role of levels of exposure

Regarding levels of exposure, the dose-response effects expected from the general trauma literature tend to be found in most studies on Palestinian youth. For example, when examining Palestinian children's (aged 9 to 16 years) responses to varying intensities of socio-political violence during the past six years, mean PTSS rates evolved from $40 \%$ after the end of the first intifada in the peace period, through $10 \%$ during the peace process and up again to $39 \%$ during the current intifada. PTSS peaked to $70 \%$ during recent shelling of the Gaza Strip (Thabet et al., 1999; Thabet, and Vostanis, 2000; Thabet, Al Gamal, Vand Vostanis, 2006; Thabet, Abu Tawahina, El Sarraj, and Vostanis, 2007). When comparing Palestinian and Israeli-Palestinian children's reactions to exposure to traumatic events, over one third of the former displayed severe to very severe PTSS compared to one fifth of the latter (Tamar and Solomon, 2005). Furthermore, some evidence also suggests a decrease in PTSS when the exposure subsides. This was the case, for example, with school-aged Israeli children whose PTSS dropped from $22 \%$ to $12 \%$ in one year when scud missile attacks ceased after the Gulf War (Schwarzwald, Weisenberg, Waysman, and Solomon, 1993). PTSS also decreased in a 30-month follow-up among displaced Israeli preschool children (Laor, Wolmer, Mayes, Gershon, Weizman, and Cohen, 1997). However, such trends are not necessarily linear. For example, PTSS was first found to increase among Iraqi children during the 13 months after their shelter had been bombed, to fall significantly only after two years (Dyregrov, and Raundalen, 1993). In short, exposure levels and more specifically dose-response effects warrant attention when attempting to understand posttraumatic stress responses in youth. Still, the current literature limits drawing conclusions about the persistency versus attenuation of symptoms because the types of trauma, length of follow-up, children's gender and age widely differ across studies. Especially regarding the latter, it should be noted that only few published studies appear to specifically pertain to Palestinian adolescents.

The role of types of exposure

Types of exposure merit further analysis given an increasing evidence-base on trauma resulting from military violence and socio-political adversities. More specifically, exposure in this context can be sub-typed into objective, subjective and media exposure (Braun-Lewensohn et al., 2009a). Objective exposure consists of observable facts that cannot be controlled by the individual. It can be further subtyped in direct, physical exposure and indirect exposure (through witnessing and relationship with a victim). Subjective exposure refers to the individual's experience of the events (immediate appraisal), regardless of their objective characteristics. 
Media exposure merits separate attention given its mix of both objective and subjective characteristics. Indeed, while watching the media implies some extent of objective exposure (namely watching real images of shelling, shooting and so forth), it is also partly controlled by the individual's choice to consult the media. In the Palestinian context, shifts in types of exposure may apply between the first (1987) and the second (2000) Al Aqsa Intifada. During the first Intifada, objective exposure appeared predominant in both its indirect-relational and direct-physical components, as evidenced by the frequency of tear gas attacks (93\%), breaking into homes (90\%), beatings of family members or self $(70 \%$ to $62 \%)$ and being personally injured (37\%) (Abu-Hein, Qouta, Thabet, and El-Sarraj, 1993). Research closer to the current study period suggests a shift toward the predominance of media and indirect, relational objective exposure. For instance, across studies, events cited by two-thirds to more than $90 \%$ of Palestinian children include seeing victims of violence on television, witnessing funerals, shootings, bombardments and shelling and injured or dead persons. A smaller proportion of youngsters report being shot by bullets (12.9\%) (Qouta et al., 2003; Thabet, Abed, and Vostanis, 2001 ).

Adolescents' objective exposure to higher levels of physical traumatizing events has been, understandably, found to elicit more adverse psychological reactions, including higher rates of PTSD, functional impairments, anxiety and substance abuse. Research however also has shown that media and indirect objective exposure also strongly contribute to youth's PTSS (Braun-Lewensohn et al., 2009a, 2009b; Dyregrov et al., 2002; Punamaki, Komproe, Qouta, ElMasri and de Jong, 2005; Thabet \& Vostanis, 2000). Taken together, these findings suggest that types of exposure may require attention when attempting to understand adolescents' psychological responses to ongoing trauma.

The role of gender

Regarding gender, girls generally appear to be more vulnerable toward PTSS than boys (Dyregrov et al., 2002; Braun-Lewensohn et al., 2009; Orla, 2003; Orlee, Boyle, and Yule,2000). Although this tendency also comes forward in the Palestinian context (e.g. Punamaki,and Puhakka, 1997; Qouta et al., 2003, Qouta, Punamaki, and El Saraaj. 2004; Thabet et al., 2001), its extent remains equivocal, with some studies suggesting no gender differences or even higher levels of posttraumatic stress in males, as in Punamaki et al.' (2005) study on peritraumatic reactions. Age may play a role in these mixed findings, since gender differences appear prevalent in studies focusing on the broad childhood period, as opposed to Punamaki et al's findings among 16 to 60 year olds. The extent of gender effects may also be trauma specific (e.g., natural disasters versus societal trauma) (Punamaki et al., 2005; Saigh, 
1991; Thabet, Abu-Nada, Shivram, Millingen, and Vostanis, 2009). Thus, posttraumatic gender effects specific ally among Palestinian adolescents merit further clarification.

The role of the current age cohort

The extent and type of age effects in youth's responses to chronic trauma exposure have remained equiv ocal too. While some studies have not found any age effects in such contexts (Saigh, 1991), according to others, both younger and older children appeared to be more vulnerable than their counterparts (e.g. Qouta et al., 2003). A child's age, therefore, may not be a risk factor in and of itself; rather, in each growth and developmental stage children and adolescents deal with both resiliencies and vulnerabilities (Berman, 2001; Braun-Lewensohn et al., 2009; Celestin-Westreich and Celestin, 2010; Finkelhor, 1995; Punamaki, 2002). Notably, the current cohort of Palestinian adolescents is characterized by having lived more than two thirds of their youth under ongoing traumatic events, having been around 10 years old when the current Al-Aqsa Intifada erupted in 2000. This implies a pronounced degree of vulnerabilities experienced throughout their childhood that may contribute tow ard elevated PTSS levels.

The role of other demographics

In an attempt to further differentiate influencing demographic factors, mainly place of residency has been considered through its simultaneous link with levels of exposure and environmental specificities. The Palestinian area of residency is mainly subdivided into Gaza city and refugee camps (both situated far away from the borders) and villages (close to the borders). Compared to those living in the villages, youth from Gaza cities or refugee camps are less likely to be exposed to physical incursions or artillery bombardments, but more to aircraft bombardments on homes, governmental buildings and streets (PCBS, 2006). The effect of place of residency on youngsters' PTSS has nonetheless yielded unclear findings to date. Thus, in one study Palestinian children living close to Israeli settlements were found to show acute levels of posttraumatic stress to an important extent (55\%) (Quota et al., 2005), while other research found children meeting the criteria of PTSD to come mainly from urban areas (Thabet et al., 2001). Furthermore, the literature evidences that adolescents in war zones can be affected through various other demographic influences, such as a lack of basic health needs, loss of family members, disruption of social networking and displacements. Few studies have examined the relationship between such demographical characteristics and the level of PTSS among adolescents in the Palestinian society (Qouta, Punamaki, and El Sarraj, 1997; Thabet, Abed, and Vostanis, 2002). 
In short, environmental and family demographic characteristics still need to be more extensively addressed when investigating Palestinian adolescents' posttraumatic responses.

Implications for current research

As comes forward from the current state of the literature, many aspects of adolescents' stress reactions to a chronic context of exposure to socio-political violence warrant further inv estigation. To this effect, the following research questions and hypotheses were addressed in the present study. It appeared relevant to first investigate levels and types of exposure, along with possible demographic variations hereof. Given the current evidence-base, we expected a majority of the Palestinian adolescents to have been exposed to more than one objective traumatic event. Given that the demographic and environmental characteristics of the Palestinian society have remained relatively understudied, possible differences in exposure according to place of residency and family demographics were to be explored. Our primary research goal then pertained to identifying the levels of posttraumatic stress specifically for Palestinian adolescents, with the expectation of these being higher than those in non-exposed populations. Finally, we set out to identify demographic factors that may affect these adolescents' PTSS. We hypothesized that girls would demonstrate higher levels of PTSS than boys, as would adolescents in higher exposed places of residency. Also, we hypothesized Palestinian adolescents' PTSS to be inversely correlated to family and environmental resources (the lower the resources, the higher the PTSS).

\section{Method}

Participants and context

This study comprised a sample of 368 Palestinian adolescents $\left(11^{\text {th }}\right.$ Grade; $M=17.3$ years; $49.2 \%$ male) living in the Gaza Strip, which is approximately 50 kilometers long and 5 to 12 kilometers wide. The Gaza strip spans a narrow zone of land along the Mediterranean Sea, between Israel and Egypt. The total population is one and a half million with a population density of 2.150 people per kilometer. Among these, 808.000 persons are registered refugees, over $55 \%$ of who live in eight refugee camps scattered across the Gaza Strip. Other inhabitants live in villages and cities of the Gaza Strip. The United Nations for Relief and Work Agency (UNRWA) provides education for 159.892 pupils, as well as health and relief services to refugees living inside and outside the camps (Thabet et al. 2006). Among the participants studied, $60 \%$ were refugee adolescents living in Jabalia refugee camp, which with a 
population of approximately 120.000, lacks basic infrastructure. Approximately one fifth $(21 \%)$ of the adolescents were from Bet-Hanon village, which is situated in a remote part of the Gaza Strip (close to the Israeli borders) and has around 45.000 inhabitants. The remaining adolescents (19\%) were from Al-Remal city, which is a relatively more prosperous urbanized neighborhood of approximately 30.000 inhabitants.

Instruments

Participants completed a standardized battery that included the following questionnaires aimed at examining the initial hypotheses.

'Demographic \& Socio-Economic Inventory'

Demographics were assessed by using a self-designed inventory that included questions regarding gender, place of residency, family size, family income, maternal and paternal education and occupation.

Gaza Traumatic Event Checklist (GTEC)

The GTEC was used to assess participants' exposure to traumatic events over the last six months. It consists of 20 traumatic events that commonly occur during the ongoing political and military violence in the Gaza Strip. The initial version was developed by the research department of the Gaza Community Mental Health Program (GCMHP) and has been used in previous studies on Palestinian children (Thabet et al. 1999, 2002). Items require dichotomous answers, yielding a range of total trauma scores from 0 to 20. This checklist has shown satisfactory split half reliability $(R=0.776)$ and internal consistency (Cronbach's alpha $=0.749$ ), Thabet et al. 2002; 2009).

The Davidson Trauma Scale (DTS)

The DTS is a self-rated scale, comprising 17 items designed to measure posttraumatic stress reactions in youngsters aged 6 to 18 years. Tailored closely to the symptom definitions of the Diagnostic and Statistical Manual of Mental Disorders, 4th edition (DSM-IV), these pertain to intrusive re-experiencing (DSM-IV criteria B), avoidance and numbness (DSM-IV criteria $C$ ) and hyper arousal reactions (DSM-IV criteria D) (American Psychiatric Association, 1994). Before application, adolescents must meet DSM-IV criteria A and $E$, namely experiencing or witnessing an extremely traumatic event. Rating is ordinal (from 'never' (0), through 'sometimes' (1) to 'often' (2)). 
Participants were given a "probable current PTSD diagnosis" if they responded with 'often' to at least one of the four 'trauma re-experiencing' items, along with at least three of the seven 'avoidance of stimuli associated with trauma' items and at least two of the six 'increased arousal' items. The DTS theoretical sum score range lies between 0 and 34. In our sample, this range was further grouped into 'none or doubtful' (score 0-8), 'mild' (score 9-16), 'moderate' (17-24) or 'severe' (25 and above). The DTS has been translated into Arabic by professional bilingual translators. It shows satisfactory reliability with a split half $\mathrm{R}$ of 0.74 and internal consistency Cronbach's alpha of 0.75 (Thabet et al. 2002, Thabet et al. 2009). The reliability in our sample also shows satisfactory with a split-half $R$ of 0.605 and Cronbach's alpha of 0.709 .

\section{Procedure}

The ethical procedures applicable to this study were followed. As required by the Palestinian Ministry of High Education, the research proposal and questionnaires were submitted before the start of the study. After receiving their approval to proceed, permission to enter the schools was gathered from the principals. Students completed the self-report questionnaires during regular class hours in the first trimester of the academic year 2006-2007. Students were introduced to the study purpose and assured of the confidentiality of all data. The participants were informed that the researcher was interested in their experience of ongoing traumatic events, that participation was voluntary and anonymous, and that they were free to withdraw their participation for any reason and at any time during the questionnaire procedure. Completion time ranged from around 35 to 45 minutes.

As indicated, data were gathered from secondary schools located in the area of Jabalia refugee camp, Bet-Hanon village and Al-Remal city. A multistage random sample design was used to reach the potential study sample, in three main phases. First, cluster random selection was applied to include all the governmental secondary schools in the above cited areas. Second, stratified cluster selection was applied on classes in which the students had been given a participation invitation (450 adolescents). Third, among those who obtained parental consent and agreed to participate, adolescents were randomly selected by choosing those sitting on the right side of the classroom desk. Thus, a representative sample of 368 Palestinian adolescents was drawn from a total of 4551 students, distributed over 115 classes ( $11^{\text {th }}$ grade) from 13 governmental secondary schools.

To avoid any dramatic changes in the political situation in Gaza that might have affected the adolescents' responses, all data were gathered within a time frame of 
two consecutive weeks. The response rate was considered to be satisfactory, with $98 \%$ of the invited adolescents agreeing to participate in the study.

Data analysis

Analyses were computed using the statistical software SPSS version 13.0. The data were analyzed using descriptive and inferential analysis. The present analyses assessed several predictors (i.e., level of exposure to traumatic events and demographic factors) for the outcome variable 'posttraumatic stress reactions'. The inferential analyses included use of independent sample t-tests and one-way ANOVA.

Results

Demographics: descriptive

Consistent with the Palestinian demography, participating adolescents were from 'large' families with $72 \%$ comprising nine family me mbers or more.

The vast majority of these families are characterized by low socio-economic levels (educational and employment), with $57.6 \%$ of fathers and $69 \%$ of mothers having completed low education (secondary school or less) in contrast to $21.5 \%$ of fathers and $13.9 \%$ of mothers having completed higher education (university graduation to postgraduate). Over one third of the adolescents' fathers were unemployed, while approximately one fourth worked as civil employees and the remainder as laborers. Approximately, four fifths of their mothers were house wives, slightly less than one fifth employees and the remainder laborers. Due to high levels of unemployment, $42 \%$ of the adolescents' families earn less than 100 euro's a month. Table 1 provides a complete overview of the sample's family de mographics. 
Table 1. Percentage and Frequencies of Demographic Characteristics $(N=368)$

\begin{tabular}{|c|c|}
\hline Demographic characteristics & $\%$ \\
\hline \multicolumn{2}{|l|}{ Gender } \\
\hline Male & 49.2 \\
\hline Female & 50.8 \\
\hline \multicolumn{2}{|l|}{ Place of residency } \\
\hline City & 18.5 \\
\hline Village & 21.2 \\
\hline Refugee camp & 60.3 \\
\hline \multicolumn{2}{|l|}{ Family size } \\
\hline Small (4 and less) & 0.8 \\
\hline Medium (5-8 members) & 27.4 \\
\hline Large (9 or more) & 71.7 \\
\hline \multicolumn{2}{|l|}{ Income } \\
\hline$<100$ Euro & 41.8 \\
\hline 101 - 300 Euro & 32.1 \\
\hline $301-600$ Euro & 16.8 \\
\hline$>600$ Euro & 9.2 \\
\hline \multicolumn{2}{|l|}{ Paternal education } \\
\hline Low (s secondary school) & 57.6 \\
\hline Medium (secondary school to entered university) & 20.9 \\
\hline High (university (post)graduation) & 21.5 \\
\hline \multicolumn{2}{|l|}{ Maternal education } \\
\hline Low (s secondary school) & 69.0 \\
\hline Medium (secondary school to entered university) & 17.1 \\
\hline High (university (post)graduation) & 13.9 \\
\hline \multicolumn{2}{|l|}{ Paternal job } \\
\hline Unemployed & 38.6 \\
\hline Worker & 17.1 \\
\hline Handcraft & 5.2 \\
\hline Employee & 27.2 \\
\hline Farmer & 3.0 \\
\hline Merchant & 5.2 \\
\hline Other & 3.8 \\
\hline \multicolumn{2}{|l|}{ Maternal job } \\
\hline House wife & 92.9 \\
\hline Worker & 3.3 \\
\hline Employee & 3.8 \\
\hline Other & 0.0 \\
\hline
\end{tabular}


Levels and types of exposure to traumatic events

This study first set out to examine the adolescents' levels and types of exposure to traumatic events. The mean number of traumatic events that any particular adolescent experienced was 9.9 (SD = 3.20). Table 2 furthermore shows that the vast majority of the adolescents were exposed to objective indirect traumatic events (implying no personal physical harm and not directly pertaining to their family) as well as media exposure. A smaller, yet sizeable proportion of adolescents were exposed to direct physical harm, through relationship with a victim, or material harm to personal belongings.

Table 2: Types of Traumatic Events experienced by Adolescents ( $N=368$ )

\begin{tabular}{|c|c|c|c|c|c|c|}
\hline Gaza Traumatic Event Checklist & Boys & & Girls & & Tota & \\
\hline & $\mathrm{N}$ & $\%$ & $\mathrm{n}$ & $\%$ & $\mathrm{n}$ & $\%$ \\
\hline 1. Hearing of sonic boom and artillery fire & 177 & $48.1 \%$ & 176 & $47.8 \%$ & 353 & $95.9 \%$ \\
\hline $\begin{array}{l}\text { 2. Watching the pictures of injured persons and killed on } \\
\text { the television }\end{array}$ & 174 & $47.3 \%$ & 177 & $48.1 \%$ & 351 & $95.4 \%$ \\
\hline 3. Watching homes explosions on television & 169 & $45.9 \%$ & 178 & $48.4 \%$ & 347 & $94.3 \%$ \\
\hline $\begin{array}{l}\text { Hearing about an incursion to your land, town, homes or } \\
\text { other }\end{array}$ & 170 & $46.2 \%$ & 164 & $44.6 \%$ & 334 & $90.8 \%$ \\
\hline 4. Witnessing the bombardment of government buildings & 165 & $44.8 \%$ & 149 & $40.5 \%$ & 314 & $85.3 \%$ \\
\hline 5. Witnessing targeted assassinations & 157 & $42.7 \%$ & 121 & $32.9 \%$ & 278 & $75.5 \%$ \\
\hline $\begin{array}{l}\text { 6. Witnessing an invasion to your land, town, homes or } \\
\text { other }\end{array}$ & 134 & $36.4 \%$ & 132 & $35.9 \%$ & 266 & $72.3 \%$ \\
\hline 7. Hearing about the killing of a friend & 146 & $39.7 \%$ & 85 & $23.1 \%$ & 231 & $62.8 \%$ \\
\hline 8. Witnessing bombardment of other people homes & 86 & $23.4 \%$ & 93 & $25.3 \%$ & 179 & $48.6 \%$ \\
\hline 9. Witnessing a friend being injured & 96 & $26.1 \%$ & 46 & $12.5 \%$ & 142 & $38.6 \%$ \\
\hline 10. Witnessing the demolishing of your friends home & 75 & $20.4 \%$ & 67 & $18.2 \%$ & 142 & $38.6 \%$ \\
\hline 12. Witnessing the invasion to your neighbor homes & 53 & $14.4 \%$ & 76 & $20.7 \%$ & 129 & $35.1 \%$ \\
\hline 13. Witnessing the killing of a close relative & 68 & $18.5 \%$ & 54 & $14.7 \%$ & 122 & $33.2 \%$ \\
\hline 14. Witnessing your land being destroyed & 57 & $15.5 \%$ & 47 & $12.8 \%$ & 104 & $28.3 \%$ \\
\hline 15. Witnessing a friend being killed & 62 & $16.8 \%$ & 35 & $9.5 \%$ & 97 & $26.4 \%$ \\
\hline 16. Witnessing the shelling of your home & 26 & $7.1 \%$ & 37 & $10.1 \%$ & 63 & $17.1 \%$ \\
\hline 17. Hearing about the killing of a close family member & 31 & $8.4 \%$ & 32 & $8.7 \%$ & 63 & $17.1 \%$ \\
\hline 18. Witnessing the killing of a close family member & 26 & $7.1 \%$ & 33 & $9.0 \%$ & 59 & $16.0 \%$ \\
\hline 19. Witnessing the bulldozing of your own home & 20 & $5.4 \%$ & 24 & $6.5 \%$ & 44 & $12.0 \%$ \\
\hline 20. Being personally injured, shot by bullets & 18 & $4.9 \%$ & 7 & $1.9 \%$ & 25 & $6.8 \%$ \\
\hline
\end{tabular}

Note: The numbers and percentages of adolescents endorsing an item are given by row. Respondents can endorse as many items as relevant on the GTEC. 
Variations in exposure according to demographics

Furthermore, possible variations in exposure to trauma according to gender, environmental and family demographics were assessed. As shown in Figure 1, gender differences emerged with boys reporting more intense exposure to traumatic events than girls (respectively, $M=10.5, S D=2.9$ and $M=9.2, S D=3.3)(t=3.93, \mathrm{df}=$ .366, $p=0.000, d=.41)$.

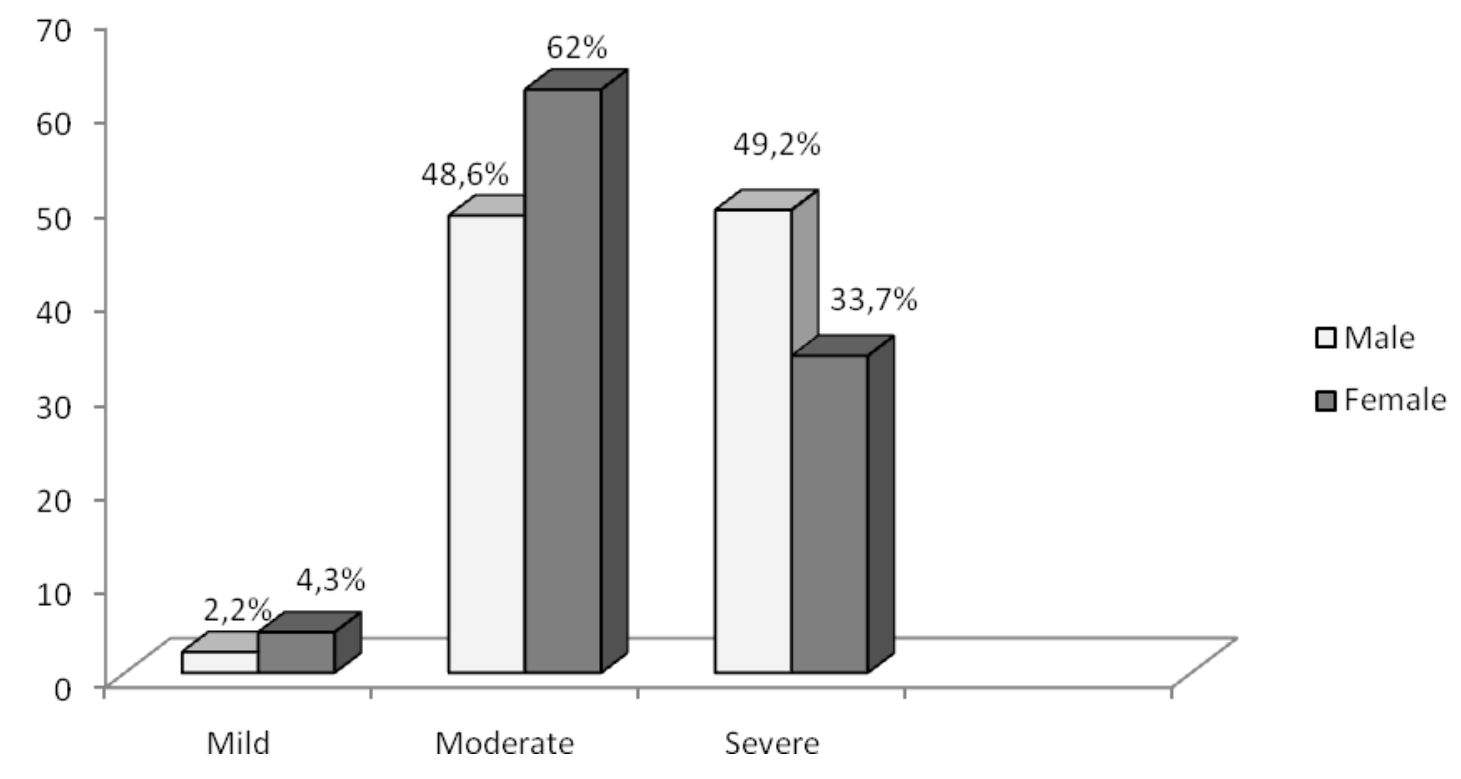

Figure 1: Exposure to Traumatic Events According to Gender

Note: Exposure is classified in mild ( $\leq 4$ events), moderate (5-10 events) and severe ( $\geq 11$ events) (Thabet et al., 2001, 2008)

The number of traumatic events experienced by adolescents also differed significantly across places of residency (Figure 2). More specifically, adolescents living in villages were more exposed $(M=11.1, S D=3.0)$ than those living in the refugee camps $(M=10.1, S D=3.2)$ or the city $(M=8.1, S D=2.5)(F=17.84(2,365)$, $M S E=9.40, p=0.000)$.

Finally, only family income was significantly associated with the degree of exposure to traumatic events. Thus, we observed a negative linear trend between level of family income and number of traumatic events ( $r=-.16 ; p=0.002)$. 


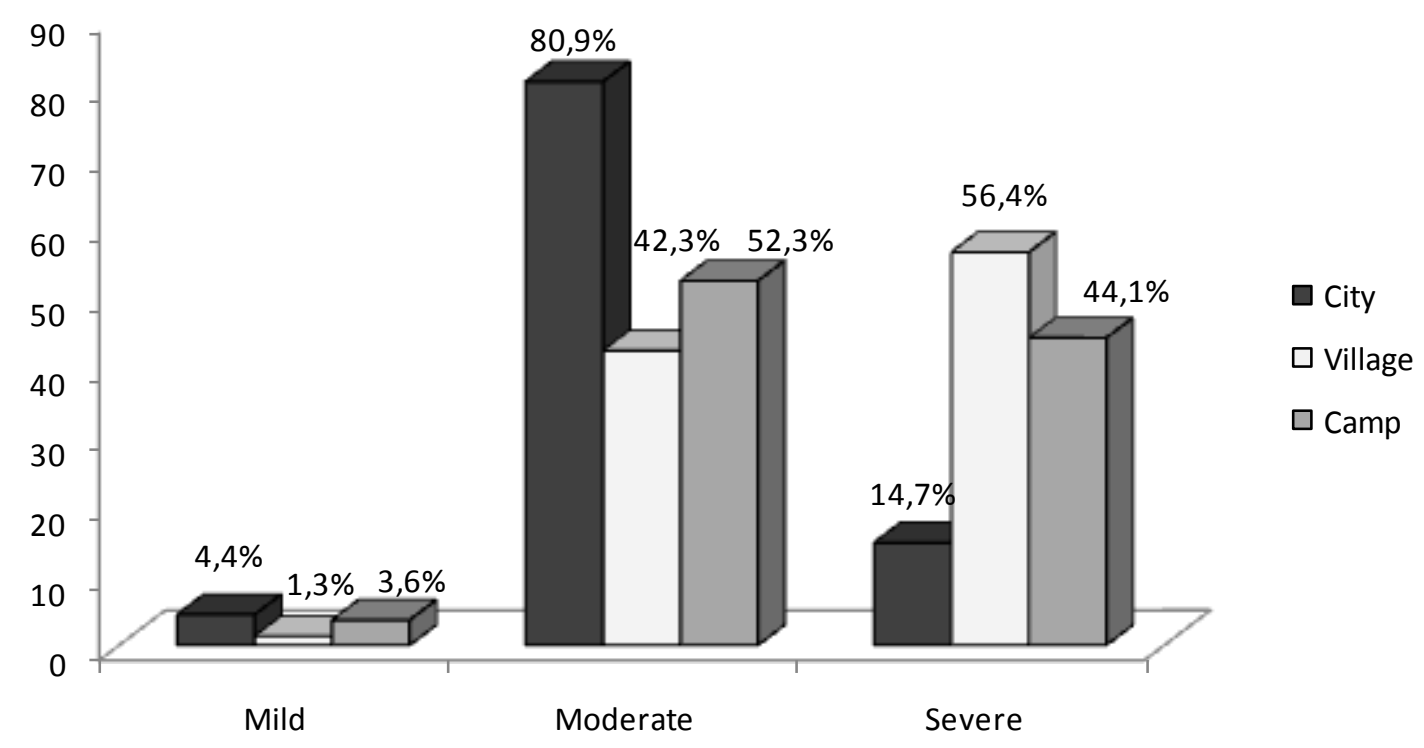

Figure 2: Exposure to Traumatic Events According to Place of Residency Note: Exposure is classified in mild ( $\leq 4$ events), moderate (5-10 events) and severe ( $\geq 11$ events) (Thabet et al., 2001, 2008)

Levels of posttraumatic stress

The primary goal was to assess adolescents' posttraumatic stress levels. Our results indicate that only less than one-tenth (9.8\%) of the adolescents showed no PTSS, whereas the majority showed mild to moderate $(40.5 \%$ and $44,3 \%$ respectively) and $5.4 \%$ severe PTSS. Taken together, this corresponds to $17.1 \%$ of the participants displaying symptoms amounting to a probable PTSD according to DSM-IV diagnostic criteria.

As shown in Table 3, a majority of the adolescents (50\% to $84 \%$ ) reported sometimes or always suffering from re-experiencing, avoiding, or arousal symptoms related to their exposure to traumatic events. Only the ability to recall experiences and to project goals along the life span reportedly remained intact for most participants. 
Table 3. Palestinian Adolescents' Posttraumatic Stress Symptoms ( $N=368$ )

\begin{tabular}{|c|c|c|c|c|c|c|}
\hline Davidson Trauma Scale (DTS) & $\mathrm{NeV}$ & & Som & times & Alwc & \\
\hline & $\mathrm{n}$ & $\%$ & $\mathrm{n}$ & $\%$ & $\mathrm{n}$ & $\%$ \\
\hline $\begin{array}{l}\text { 1. Have you had painful images memories or thoughts of the } \\
\text { event? }\end{array}$ & 58 & 15.8 & 185 & 50.2 & 125 & 34.0 \\
\hline 2. Have you had distressing dreams of the event? & 119 & 32.3 & 142 & 38.6 & 107 & 29.1 \\
\hline 3. Have you felt as though the event was re-occurring? & 83 & 22.6 & 118 & 32.2 & 166 & 45.2 \\
\hline $\begin{array}{l}\text { 4. Have you been upset by something which remind you of } \\
\text { the event? }\end{array}$ & 65 & 17.7 & 109 & 29.6 & 194 & 52.7 \\
\hline $\begin{array}{l}\text { 5. Have you been avoiding thoughts or feelings about the } \\
\text { event? }\end{array}$ & 94 & 25.5 & 113 & 30.7 & 161 & 43.8 \\
\hline $\begin{array}{l}\text { 6. Have you been avoiding doing things or going into } \\
\text { situations which remind you } \\
\text { about the event? }\end{array}$ & 98 & 26.6 & 125 & 34.0 & 145 & 39.4 \\
\hline $\begin{array}{l}\text { 7. Have you found yourself unable to recall important parts } \\
\text { of the event? }\end{array}$ & 310 & 84.2 & 35 & 9.5 & 23 & 6.3 \\
\hline 8. Have you had difficulty enjoying things? & 135 & 36.7 & 96 & 26.1 & 137 & 37.2 \\
\hline 9. Have you felt distant or cut off from other people? & 191 & 51.9 & 106 & 28.8 & 71 & 19.3 \\
\hline 10. Have you been unable to have sad or loving feeling? & 161 & 43.8 & 141 & 38.3 & 66 & 17.9 \\
\hline $\begin{array}{l}\text { 11. Have you found it hard to imagine along life span } \\
\text { fulfilling your goals? }\end{array}$ & 192 & 52.2 & 114 & 31.0 & 62 & 16.8 \\
\hline 12. Have you had trouble falling asleep or staying a sleep? & 110 & 29.9 & 116 & 31.5 & 142 & 38.6 \\
\hline 13. Have you been irritable or had outbursts of anger? & 136 & 37.0 & 138 & 37.5 & 94 & 25.5 \\
\hline 14. Have you had difficulty concentrating? & 118 & 32.1 & 160 & 43.4 & 90 & 24.5 \\
\hline $\begin{array}{l}\text { Have you felt on edge, been easily distracted, or had to stay } \\
\text { on guard? }\end{array}$ & 78 & 21.2 & 161 & 43.7 & 129 & 35.1 \\
\hline 15. Have you been jumpy or easily startled? & 116 & 31.5 & 125 & 34.0 & 127 & 34.5 \\
\hline Have you been physically upset by reminders of the event? & 171 & 46.5 & 141 & 38.3 & 56 & 15.2 \\
\hline
\end{tabular}

Note: The numbers and percentages of adolescents endorsing an item as 'never', 'sometimes' or 'always' are given by row.

Differences in posttraumatic stress according to personal and demographic factors

Finally, we aimed to analyze whether PTSS levels varied according to personal and demographic factors.

Regarding gender, no signific ant differences in PTSS were found between boys ( $M=$ 16.3, $S D=5.3)$ and girls $(M=15.8, S D=5.6)(t=862$; $d f=366, p=0.39)$. Similarly, adolescents showed no significant differences in PTSS levels across places of residency ( $w$ ith $M=15.9, S D=5.0$ for city, $M=16.6, S D=6.0$ for village and $M=15.9$, $S D=5.4$ for camp residents $(F=532,(2,365), P=.588)$. Moreover, our findings showed no significant relationship between PTSS and the other investigated 
demographic factors, i.e. respectively family size $(F=.656,(2,365), p=.519)$, family income $(F=1.839,(2,365), P=.140)$, paternal education $(F=2.527,(3,364), P=$ .057), paternal occupation $(F=.488,(6,361), \mathrm{P}=.817)$, maternal education $(\mathrm{F}=$ $1.236,(3,364), p=297)$ or maternal occupation $(F=.411,(2,365), p=.664)$.

\section{Discussion}

This study set out to examine Palestinian adolescents' posttraumatic stress and possible situational and demographical determinants hereof. To do so, the levels and types of exposure, along with variations across personal, environmental and family demographics needed to be explored first, as discussed hereafter.

Levels and types of exposure

On average, the investigated 17-year old Palestinian adolescents had experienced around ten traumatic events during their lifetime. These findings are consistent with previous research showing that Palestinian youth have experienced significant exposure to socio-politic al violence (Macksoud, Aber, and Cohen, 1996; Punamaki, Qouta, and El Sarraj, 1997; Quota et al., 2005; Thabet et al., 2001). According to the classification of exposure levels convened by a consensus meeting of Palestinian mental health professionals, this corresponds to a mean level of moderate-to-severe exposure (Thabet et al., 2001,2008).

The vast majority of the investigated adolescents were exposed to objective yet indirect traumatic events (no personal physic al or family harm) and media exposure, consistent with the expectation of a shift in type of exposure in this age cohort. The high levels of media exposure may furthermore indicate a lack of leisure activities for adolescents (Thabet et al., 2001).

Variations in levels of exposure according to demographics

Primarily, adolescents' gender and place of residency determined levels of exposure to trauma, with boys and those living in the villages experiencing more traumatic events. These findings appear consistent with other research (Qouta, Punamaki, and El Sarraj, 1995; Punamaki et al., 2005). Regarding gender, this difference in exposure may result from Palestinian girls being culturally more sheltered (kept inside the homes) and less likely to participate in political activities compared to boys. As indicated before, the higher exposure for adolescents living in villages seems to result from the political implications of their geographical location. These findings may also 
suggest cohort influences, as they are consistent with the more recent research suggesting higher levels of exposure for children living in the rural area compared to earlier findings showing no relation hereof with place of residency (Qouta el al., 1995). Not surprisingly, low income families disposing of lesser resources were also at risk for higher levels of exposure to traumatic events, consistently with findings, for example, among low income families in Lebanon (Macksoud, 1996). Whether the absence of significant relationships of levels of exposure with the other family demographics is robust or dependent on the overall levels of exposure remains to be further investigated.

Levels of posttraumatic stress among Palestinian adolescents

Our main goal was to assess the levels of posttraumatic stress among the Palestinian adolescents. As expected, these appeared to be high, amounting to around one fifth of the adolescents displaying probable PTSD and a vast majority of them suffering from substantive re-experiencing, avoiding, and arousal symptoms. Given these adolescents' high levels of trauma exposure, these findings appear consistent at first sight with the current literature base concerning dose-response effects. Considering that their exposure included high levels of indirect objective events and the mixed-type media exposure, the findings especially concur with research showing that these types also exert adverse effects in settings of prolonged individually and collectively experienced sociopolitical violence. By themselves, these findings warrant the development of prevention and intervention programs geared at informing youth about PTSD and its implications and helping them deal with it (Braun-Lewensohn et al., 2009a; Celestin-Westreich \& Celestin, 2010; Elbedour, Anthony, Ghannam, Janine and Abu Hien, 2007; Powers et al., 2010; Quota et al., 2007; Thabet et al., 2007).

Posttraumatic stress symptoms according to gender

The absence of significant gender differences in PTSS in our sample, despite boys' significant higher trauma exposure, in turn, appears to contrast with the general literature-based expectations. At closer analysis, it may result from a compensation effect, with boys' higher exposure contributing to higher PTSS, thus leveling out girls' typically higher PTSS levels. Together with the earlier discussed equivocal outcomes to this regard in the Palestinian context, our results may also suggest the need to take into account the contextual factors when considering gender effects. For example, a further explanation may lie in the combination with the age cohort, whereby dose-response effects possibly attain a ceiling after chronic exposure and thus level out stress responses between boys and girls. 
Posttraumatic stress symptoms according to demographic factors

The investigated adolescents furthermore did not differ significantly in PTSS levels across place of residency, despite village residents being more exposed than refugee camp and city residents. These findings are consistent with some studies conducted on Palestinian children, which document more severe PTSS among children who are living in the more exposed areas such as those close to Israeli settlements, but not with others that document more PTSS in the urban areas or in refugee camps (Elbedour., 2007; Qouta et al., 2004; Thabet et al., 2002, 2009). Adolescents' PTSS-levels were not affected either by the negative link between family income and exposure levels. The absence of linkages with any of the other investigated demographics (such as family size, parental education and occupation) remains consistent in the first place with the absence of any differences in levels of exposure to this regard.

Taken together from the aforementioned risk-resiliency FACE model's perspective of youth's cognitive-emotional adjustments to trauma exposure, ceiling effects in the dose-response principle may provide a first explanation for a fading out of PTSSdifferences among adolescents having experienced prolonged individual and collective exposure throughout childhood, even when coming from variously exposed residency and family income backgrounds. Stated differently, although not mutually exclusively, mediating dynamics such as adolescents' primary attribution and coping processes, may lead to equifinal PTSS outcomes across circumstances through different cognitive and emotional pathways, as evidenced in developmental psychopathology and recent research specific to chronic trauma exposure (Braun-Lewensohn et al., 2009a, Braun-Lewensohn et al., 2009b, CelestinWestreich and Celestin, 2010; Cummings et al., 2000; Elbedour et al., 2007; Powers et al., 2010; Qouta et al., 2007). Evidently, such assumptions need to be tested in further research.

Study limitations and future direction

Several limitations apply to the present study. First of all, the data were not gathered from multiple data sources (e.g., teachers, parents, peers), but were based only on adolescents' own evaluations. The multi-informant method would contribute to achieving a more complete evaluation of these youths' functioning. Also, it should be noted that no Palestinian control group was av ailable since the whole Palestinian population is affected by the ongoing Al-Aqsa Intifada. Particularly, this study utilized a cross-sectional design and, thus, it is difficult to infer any cause-effect relationships. 
Finally, since only $11^{\text {th }}$ grade or 17-year old adolescents were investigated, different outcomes may apply to younger or older adolescents.

\section{Conclusion}

This study analyzed the impact of ongoing traumatic sociopolitical events on Palestinian adolescents' posttraumatic stress reactions (PTSS and PTSD) according to event-related and demographic factors.

The investigated 11 th grade adolescents experienced a mean number of around 10 traumatic events throughout their lifespan, with boys being significantly more exposed than girls, as were those living in villages compared to Gaza city or refugee camp residents. Adolescents mainly and pervasively reported objective, nonpersonal material and media exposure. Around one-fifth also experienced direct, physical exposure and exposure through injury and death of relatives. In this context of intense continual exposure, more than half of the investigated adolescents living in the Gaza Strip reported moderate to high levels of posttraumatic stress symptoms, for one fifth among them this amounted to a probable posttraumatic stress disorder. Remarkably, these PTSS levels were not primarily linked to their differences in exposure levels according to gender, place of residency and family income.

From a research perspective, these findings suggest two major pathways for enhancing comprehension of middle to late Palestinian adolescents' postraumatic stress reactions. First, it may be that the dose-response principle attains a ceilingeffect when adolescents attempt to adapt to lifelong exposure. Second, primary attributions and coping strategies may moderate adolescents' cognitive-emotional dynamics, leading to similar posttraumatic stress responses despite different levels and types of exposure. From a practice perspective, these findings underscore the pervasive need for prevention and intervention programs to help Palestinian adolescents deal with the substantive challenges of growing into adults in a context of prolonged individual and collective exposure to sociopolitical trauma. Last but not least, since around one tenth of the investigated adolescents reported relatively low levels of posttraumatic stress, further identification of resiliency factors and dynamics is also strongly recommended.

\section{References}

Abu-Hein, F., Qouta, S., Thabet, A., \& Sarraj, E. (1993). Trauma and mental health of children in Gaza. British Medical Journal, 306, 1129. American Psychiatric Association. 
Diagnostic and Statistical Manual of Mental disorders, Fourth Edition. Washington, DC, 1994.

Boothby, N., Upton, P., \& Sultan, A. (1992). Adolescents of Mozambique: The cost of Survival \{special Issue\}

Braun-Lewensohn, O., Celestin-Westreich, S., Celestin, L.P., Verleye, G., Verté, D., \& Ponjaert-Kristoffersen, I., (2009a). Coping Styles as Moderating the Relationships between Terror Attacks and Well-Being Outcomes. Journal of Adolescence, 32, 585 - 599.

Braun-Lewensohn, O., Celestin-Westreich, S., Celestin, L.P., Verte, D., \& PonjaertKristoffersen, I. (2009b). Adolescents' Mental Health Outcomes According to Different Types of Exposure to Ongoing Terror Attacks. Journal of Youth and Adolescence, 38, 850862.

Celestin-Westreich, S., \& Celestin, L. P. (2010) Kind, Opvoedings- en Gezinsdiagnostiek in FACE ${ }^{{ }_{-}}$perspectief [Child, Parenting and Family Assessment in FACE ${ }^{\odot-p e r s p e c t i v e] . ~}$ Leuven/Den Haag: ACCO.

Cummings, E.M., Davies, P.T., \& Campbell, S.B. (2000). Developmental psychopathology and family process. Theory, research and clinical implications. New York: The Guilford Press.

Davidson, J., \& Foa, E.B., ed. (1996). Post traumatic stress disorder; DSM-IV and beyond. Washington, DC.: American Psychiatric Press.

Dyregrov, A., \& Raundalen, M. (1993). A longitudinal study of war-exposed children in Iraq. Presented at the international conference on mental health and the challenge of peace, 13-15 September, 1995, Gaza.

Dyregrov, A., Gjestad, R., \& Raundalen, M. (2002). Children exposed to warfare: A longitudinal study. Journal of Traumatic Stress, 15, 59-68.

Elbedour, S., Anthony, J., Ghannam, J., Janine, A., \& Abu Hien, F. (2007). Post-traumatic stress disorder, depression, and anxiety among Gaza Strip adolescents in the wake of the second U prising (Intifada). Child Abuse and Neglect, 31, 719-729.

Finkelhor, D. (1995). The victimization of children: A developmental perspective. American Journal of Orthopsychiatry, 65, 177-193.

Kalantari, M., \& Vostanis, P. (2010). Behavioural and emotional problems in Iranian children four years after parental death in an earthquake. International Journal of Social Psychiatry, 56 (2), 158-167. 
Khamis, V. (2000). Posttraumatic stress disorder among school age Palestinian children. Child Abuse \& Neglect, 29, 81-95.

Kinzie, J., Sack, W., Angell, R., Manson, S., \& Rath, B. (1986). The psychiatric effect of massive trauma on Cambodians children: The children. Journal of the Academy of child psychiatry, 25, 370-376.

Laor, N., Wolmer, L., Mayes, L., Gershon, A., Weizman, R., \& Cohen, D. (1997). Israeli preschools under scuds: A 30 -month follow- up. Journal of American Academy of child Adolescents Psychiatry, 36, 349-356.

Macksoud, M., Aber, J., \& Cohen, I. (1996). The war experience and psychological development of children in Lebanon. Child Development, 67, 70-88.

Orlee, U., Boyle, S., \& Yule, W., (2000). Risk factors for long-term psychological effects of a disaster experienced in adolescence: predictors of post traumatic stress disorder. Journal of Child Psychology and Psychiatry, 41, 969-979.

Palestinian Central Bureau of Statistics (PCBS, 2006).

Powers, M.B., Halpern, J.M., Ferenschak, M.P., Gillihan, S.J., \& Foa, E.B. (2010). A meta analytic review of prolonged exposure for posttraumatic stress disorder. Clinical Psychology Review, 30(6), 635-641.

Punamaki, R. (2002). The uninvited guest of war enters childhood: Developmental and personality aspects of war and military violence. Traumatology, 8, 30-54.

Punamaki, R., \& Puhakka, T. (1997). Determinants and effectiveness of children's coping with traumatic experiences. International Journal of developmental Behavior, 21, 349370.

Punamaki, R., Qouta, S., \& El Sarraj, E. (1997). Relationships between traumatic events, children's gender, political activity, and perception of parenting style. International Journal of Behavioral Development, 21, 91-109.

Punamaki, R., Komproe, I.H., Qouta, S., ElMasri, M., \& de Jong, J. (2005) The role of peritraumatic dissociation and gender in the association between trauma and mental health in a Palestinian community sample. American Journal of Psychiatry, 162, 545-561. 
Qouta, S., Punamaki, R., \& El Sarraj, E. (1995). The relations between traumatic experiences, activity, and cognitive and emotional response among Palestinian children. International Journal of Psychology, 30, 289-304.

Qouta, S., Punamaki, R., \& El Sarraj, E. (1997). House demolition and mental health: Victims and witnesses. Journal of Social Distress and The Homeless, 6, 203-211.

Qouta, S., Punamaki, R., \& El Sarraj, E. (2003). Prevalence and determinants of PTSD among Palestinian children exposed to military violence. European Child \& Adolescent Psychiatry, 12, 265-272.

Qouta, S., Punamaki, R.L., El Saraaj. E. (2004). Prevalence of PTSD among Palestinian Adolescents in Gaza Strip. Arabpsynet Journal, 2, 8-13.

Qouta, S., Punamaki, R.L., \& El Saraaj. E. (2005). Mother-child expression of psychological distress in war trauma. Clinical Child Psychology and Psychiatry, 10, 135-156.

Qouta, S., Punamäki, R., Montgomery, E., \& El Sarraj, E. (2007). Predictors of Psychological distress and positive resources among Palestinian adolescents: trauma, child, and mothering characteristics. Child Abuse \& Neglect, 31, 699-717.

Saigh, P. (1991). The development of post traumatic stress disorder following four different types of dramatization. Behavior Research and Therapy, 29, 213-216.

Schwarzwald, J., Weisenberg, M., Waysman, M., \& Solomon, Z. (1993). Stress reaction of school-aged children to the bombardment by SCUD missiles. Journal of Abnormal Psychology, 102, 404-410.

Smith, P., Perrin., S., Yule, W., \& Rabe-Hesketh, S. (2001). War exposure and maternal reactions in the psychological adjustment of children from Bosnia- Herzegovina. Journal of Child Psychology \& Psychiatry \& Allied Disciplines, 42, 395-404.

Tamar, L., \& Solomon, Z. (2005). Palestinian youth of the Intifada: PTSD and future orientation. American Academy of Children and Adolescents Psychiatry, 44, 1176-1 183.

Thabet, A., \& Vostanis, P. (2000). Post traumatic stress disorder reactions in children and adolescents of war: A longitudinal study. Child Abuse \& Neglect, 24, 291-298.

Thabet, A., Abed, Y., \& Vostanis, P.(1999). Posttraumatic stress reactions of war. Journal of Child Psychology and Psychiatry, 40, 385-391. 
Thabet, A., Abed, Y., \& Vostanis, P. (2001). Effect of trauma on the mental health of Palestinian children and mothers in the Gaza Strip. Eastern Mediterranean Health Journal, 7, 413-421.

Thabet, A., Al Gamal, H., \& Vostanis, P. (2006). Palestinian mothers' perceptions of child mental health problems and services. World psychiatry, 108-112.

Thabet, A., Abed, Y., \& Vostanis, P. (2002). Emotional problems in Palestinian children living in a war zone: a cross-sectional study. The Lancet, 359, 1801-1804.

Thabet, A., Abu Tawahina, A., El Sarraj, E., \& Vostanis, P. (2007). Exposure to war trauma and PTSD among parents and children in the Gaza Strip. European Child \& Adolescent Psychiatry, 653, 211-220.

Thabet, A., Abu-Nada, I., Shivram, E., Millingen, E., \& Vostanis, P. (2009). Parenting Support and Posttraumatic Stress Disorder on Children of a War Zone. International Journal Of Social Psychiatry, 3, 226-237.

About the authors:

Ibrahim Abu-Nada, holds a Masters Degree in mental health. He has contributed in published articles in international Journals. He is currently undergoing Doctoral training in the Department of Clinical and Lifespan Psychology at the Vrije Universiteit Brussels (VUB)

Address for correspondence: Ibrahim Abu-Nada, Department of Clinical and Lifespan Psychology, Vrije Universiteit Brussels (VUB), Pleinlaan 2,1050 Brussels, Belgium.

E-mail: Ibrahim.abunada@vub.ac.be

Prof. dr. Smadar Celestin-Westreich, PhD., is an Associate Professor of Psychology at the Vrije Universiteit Brussels. She also directs the multi-site FACE ${ }^{\circ}$-program for youth and their families. She has (co-)authored several textbooks and journal publications amongst others on posttraumatic stress and coping. E-mail: Smadar.Westreich@vub.ac.be Website: http://www.faceprogram.com

Prof. dr. Wim Van den Broeck, PhD., is an Associate Professor of Psychology at the Vrije Universiteit Brussels. His research interests and publications pertain to methodology, reading development and learning disabilities.

Dr. Leon-Patrice Celestin, psychiatrist, received his M.D. at the University of Brussels (ULB) and is currently Hospital Practitioner in Paris, France. He also directs the FACE ${ }^{\circ}$-program's sections on posttraumatic stress, Bipolar Disorders, ADHD and addictions through the lifespan; on which he has co-authored book (chapters) and journal publications. 